\title{
Volatility Modeling and Forecasting of Istanbul Gold Exchange (IGE)
}

\author{
Gaye Hatice Gencer $^{1} \&$ Zafer Musoglu ${ }^{1}$ \\ ${ }^{1}$ Department of Business Administration, Faculty of Economics and Administrative Sciences, Yeditepe University, \\ Istanbul, Turkey \\ Correspondence: Gaye Hatice Gencer, Department of Business Administration, Faculty of Economics and \\ Administrative Sciences, Yeditepe University, Istanbul, Turkey. Tel: 90-216-578-1700. E-mail: gaye70@yahoo.com
}

Received: February 10, 2014

Accepted: February 26, $2014 \quad$ Online Published: March 31, 2014

doi:10.5430/ijfr.v5n2p87

URL: http://dx.doi.org/10.5430/ijfr.v5n2p87

\begin{abstract}
In this study, we model the volatility dynamics of Istanbul Gold Exchange with several GARCH models, which incorporate asymmetry and long-range dependence in the conditional volatility. We use daily spot prices of the gold exchange from January 4, 2006 to November 20, 2013. In addition, forecasting performances of the models are evaluated based on three commonly used measures. We examine the out-of-sample predictions for 1,5 and 20-days ahead as the portfolio managers usually focus on longer horizons (20-days) as well as relatively short horizons ( 1 and 5-days ahead). The forecasting results point out the superior performance of EGARCH and CGARCH models. Hence our results provide useful information for investors and portfolio managers to consider asymmetric reactions to the news and long-range dependence property of the gold market in Turkey.
\end{abstract}

Keywords: gold market, volatility modeling, forecasting, Turkey

\section{Introduction}

Gold is a very scarce element with unique properties which make it irreplaceable in many technical applications. As it is indestructible, World Gold Council 2010 reports estimate an approximate 168,300 tons of gold mined in history existing in one form or another. Jewelry is the main and biggest industry for the use of gold as a commodity, wherein about $50 \%$ of all above ground stocks are stored. Gold is also used as a commodity in technological devices and applications from electronics and computers to medical appliances constituting approximately $12 \%$ of all above ground stocks (World Gold Council 2010). Besides the commodity use of gold, it is perceived as an investment asset, a medium of exchange and a store of wealth. The financial market for gold is vigorous, where it also serves as a high quality collateral. Private investments and official sector holdings (mainly central banks) account for about $36 \%$ of all above ground stocks which construct the global financial market in gold (World Gold Council 2010). Given the fact that the global gold market offers significant liquidity and a steady supply, central banks hold immense reserves in gold, following US dollar and Euro denominated assets. Furthermore, gold has no credit risk and the stable supply of gold ensures its enduring value, which provides attractive benefits of wealth preservation. For the past 150 years, gold has been acting as an anchor for central bank monetary bases.

The supply of gold is sustained by mining, recycled gold and net official sector sales. Unlike the supply conditions in oil, gold mine productions are geographically diversified on all continents. Hence, mining concentration risk and supply shocks are limited. Recycled gold supply comes from previously processed gold items which are melted and refined for future processing and resale in the gold market. Jewelry is the predominant source of recycled gold. Political and economic conditions affecting price volatility have a direct impact on the supply of recycled gold. Central banks as the pivot of the official sector sell gold to rebalance their reserve portfolios from time to time.

The investors in the global gold market have disparate motivations, changing from long-term strategic investments to inflation hedging or safe-haven investments against other financial assets. Gold is a very unique investment asset and as there is no sovereign credit risk in gold, at times of political unrest, political disputes and wars, it is seen as the safest alternative.

This study investigates volatility modeling and forecasting of Istanbul Gold Exchange on a daily basis. We employ several GARCH models to analyze dynamic modeling and forecasting of the gold price volatility. The models which take asymmetry and long-range dependence into account, allow us to examine different characteristics of the gold market in Turkey. Our results posit that inverted asymmetry and long-range dependence exist in the conditional 
volatility process of the gold market. The forecasting results indicate that different forecast error measures point out the superior out-of-sample performance of the EGARCH and CGARCH models for all the horizons, i.e. 1, 5 and 20-days-ahead, producing the lowest forecast errors. Our results are indicative for investors and portfolio managers to optimize and diversify their portfolio risks.

The remaining of the study is as follows: In part 2, we give information about the IGE. Part 3 presents the literature review. Part 4 describes the methodology for GARCH models and forecast error measures. Part 5 portrays the data. In part 6, we discuss the empirical results and finally, Part 7 concludes the paper.

\section{Istanbul Gold Exchange (IGE)}

Private investments in gold have a very long tradition in the Turkish culture. Some socio-cultural practices accompanied with volatile and shallow financial markets lead gold to have an indispensable position as a financial asset. Golden jewelry is considered as financial investments and still today, gold is valued as a high quality investment by most of the population. Between 1995 and 2012 Turkey has imported 2,693 tons of gold and has been among the top ten gold importing countries in the world (Istanbul Gold Exchange 2012). Turkey ranks as the $13^{\text {th }}$ in the world with its 441.5 tons of gold reserves following the European Central Bank (World Gold Council 2013). Moreover in 2013 Turkey has imported 350 tons of gold much higher than its average of 150 tons.

The Istanbul Gold Exchange (IGE) officially started its operations on July 26, 1995. The main objectives of the IGE are integrating the Turkish gold market with the international markets and promoting gold based securities in the financial system. The IGE ensures that the imported gold bars meet the generally accepted standards and that the local prices are in full compliance with the international markets. The IGE has become an associate member of the London Bullion Market Association (LBMA) in March, 2008 and the domestic production of precious metals and non-standard precious metals fully conformed to the Communique of Refineries and Standards of Precious Metals dated November 18, 2006. Very recently, in 2013, Istanbul Gold Exchange merged with Istanbul Stock Exchange under the body of Borsa Istanbul. All precious metals transactions take place within the related divisions of Borsa Istanbul which are the "Precious Metals Market" for spot trading and the "Precious Metals Lending Market" for lending transactions (Istanbul Gold Exchange 2012).

\section{Literature Review}

The recent financial crisis of 2007-2009 caused stock markets in the major economies to descend simultaneously. The literature on financial contagion argues that at times of severe crisis stock markets co-move even though perfect market integration between international markets does not exist (Dornbusch et al., 2000; Francis et al., 2008; Chandar et al., 2009). As a consequence, investors are obliged to redesign their portfolios away from equities into safer investments such as gold. Thus, determining the channels of shock and volatility transmission from one market to another is very important for international investors.

The interest in studying gold dates far back and one of the pioneering researches is done by Jaffe (1989) who conclude that adding gold to a portfolio increases the investment efficiency. Precious metals in general are widely studied, including silver, palladium, platinum and copper mostly. McKenzie et al. (2001) evidence no asymmetric effects on the returns of precious metals, while Hillier et al. (2006) document that precious metals are strong hedges at times of adverse market conditions. Likewise the studies of Conover et al. (2009), Riley (2010), Hammoudeh et al. (2011) highlight the advantages of precious metals in improving portfolio performance. Hammoudeh and Yuan (2008) analyze the conditional volatility of gold, silver and copper, and report more persistent conditional volatility with lower leverage effects for gold and silver in comparison to copper. Hammoudeh et al. (2010) report both short-term and long-term correlation dependencies and interdependencies between gold, silver, palladium and platinum. Morales and Andreosso-O'Callaghan (2011) document linkages between precious metal markets (gold, silver, platinum, and palladium) where gold has a dominating effect in general.

Morales (2008) use Generalized Autoregressive Conditional Heteroscedastic (GARCH) and exponential GARCH (EGARCH) models to examine volatility dynamics in precious metals market and document that although there exists volatility persistence among returns of precious metals, there is little evidence for the effect of precious metals on gold returns. Baur and McDermott (2010) investigate the role of gold in the global financial system between the period from 1979 to 2009 and conclude that at times of crisis gold is both a strong safe haven and a hedge for most developed markets, especially the European and the US markets, but not in Japan, Canada, and Australia. In another study, Baur and Lucey (2010) come up with the same results in German, UK and US markets on a data sample ranging from 1995 to 2005. Arouri et al. (2012) study gold, silver, palladium and platinum markets and adduce that long memory can explain the conditional volatilities of these commodities far better than structural breaks as the 
conditional returns and volatilities exhibit a long-range dependence. Hood and Malik (2013) analyze the hedging and safe haven properties of precious metals in the case of US stock market between 1995 and 2010 and they ascertain that only gold possesses a hedge and weak safe haven properties.

Moreover Lawrence (2003) highlight whether gold returns are correlated to economic activity, financial assets and other commodities using vector autoregressive (VAR) model. Results reveal that there is no significant correlation between gold returns and changes in macroeconomic variables. Also he finds out that gold returns are less correlated with equity and bond returns than other commodities' returns. McCown and Zimmerman (2006) document gold as a "zero beta asset" and an inflation hedge with mean returns higher than Treasury bill returns between 1970 and 2003. Capie et al. (2005) aver that gold acts as an exchange rate hedge against US dollars. Likewise Joy (2011), Ghosh et al. (2004), Levin et al. (2006) and Batten et al. (2010) report gold as a hedge instrument against US dollars. Kitchen (1996) asserts that gold price reacts positively to announced budget deficit projections over a sample period between 1981 and 1994. Cai et al. (2001) examine the volatility in gold futures in the US and report GDP (gross domestic product) and CPI (consumer price index) as important factors in impelling volatility. There is also a strand of literature which discusses gold as a hedge instrument in the context of international inflation due to high oil prices and the devaluation of the US dollar against the currencies of oil producing countries (Mahdavi and Zhou, 1997; Tully and Lucey, 2007; Nakamura and Small, 2007; Hammoudeh and Yuan, 2008; Soytas et al., 2009; Sari et al., 2010; Narayan et al., 2010; Morales and Andreosso-O'Callaghan, 2011). Shafiee and Topal (2010) argue that between 1968 and 2008 there have been two jumps in oil prices, the first one in 1979-1980 and the second one in 2007-2008 which are both followed by jumps in gold prices. Zhang and Wei (2010) elucidate a unidirectional Granger causality from oil market to gold price volatility and report a very high significant positive correlation between the two markets over their sample period 2000-2008.

Furthermore it is essential to analyze the reactions of assets to positive and negative shocks. As put forth by Hood and Malik (2013), volatility in stock markets is asymmetric which means that negative shocks display more profound effects on conditional volatility than positive shocks. As a result returns and conditional volatility are negatively correlated (Hood and Malik, 2013). This can be explained by leverage and volatility feedback effects. Christie (1982) is one of the incipient researchers to explain the asymmetric behavior of the equity markets pertinent to leverage hypothesis, arguing that a price decrease in the stock would also decrease the market value of the firm, increasing its financial leverage and risk (volatility). Volatility feedback effects are best described by Campbell and Hentschel (1992) who vindicate that "news" escalate current volatility and surge future volatility as volatility dynamics exhibit persistency. Increased volatility always leads to higher discount rates, declining the equity prices. Bekaert and Wu (2000) argue that the asymmetry in equity markets is the result of the simultaneous impact of the leverage and volatility feedback effects. Baur (2011) find that, in the case of the gold market, positive shocks increase the volatility by more than negative shocks in ascription to safe haven property. It is hypothesized that if the price of gold rises, investors perceive this as a signal of increased uncertainty of financial and macroeconomic conditions. Thus, positive gold return shocks scale up the volatility by more than negative return shocks.

Mills (2003) manifests that daily gold prices exhibit short-run persistence underlining the importance of long-run correlations in volatility scaling. Canarella and Pollard (2008) report the superiority of APGARCH model to apprehend the long memory features in gold returns where good news have a stronger impact on volatility than bad news. Using different GARCH models, Tully and Lucey (2006) analyze spot and future prices of gold and important economic variables. They provide an evidence of best fit of asymmetric power GARCH model which incorporates an estimated power term and an unrestricted asymmetry term. Chkili et al. (2014) explore the volatility dynamics in four commodity markets including gold, silver, natural gas and crude oil between 1997 and 2011, conducting both linear and non-linear models. They conclude that FIAPARCH model gives more accurate forecasting results in modeling both the long memory and the asymmetry effects. Their results underlie the fact that the impact of positive shocks is stronger than negative shocks with lower persistence in the case of precious metals contrary to the findings of crude oil and natural gas. Trück and Liang (2012) study the volatility dynamics of gold prices conducting different GARCH models and figure out the TARCH model as the best one for its in-sample forecasting results.

\section{Methodology}

\subsection{GARCH Model}

Most of the financial time series have a tendency for volatility to appear in bunches known as volatility clustering. Large returns of either sign are followed by large returns and small returns of either sign are followed by small returns. Brooks (2008) explains this as the information arrivals, driving price changes themselves occur in bunches. The data displaying unequal variance in the error term is heteroscedastic thus least squares models cannot be used. 
Autoregressive Conditional Heteroscedastic (ARCH) model was developed by Engle (1982) to analyze financial and economic time series and to forecast their volatility. An extension of the ARCH model is developed by Bollorslev (1986) as generalized ARCH (GARCH) model which provide that conditional current variance is dependent on past conditional squared residuals and past conditional variance.

GARCH models have many implications in the field of finance and provide many advantages over linear models. Firstly, GARCH models can replicate fat tails usually observed in financial data. It is well known that the distribution of many high frequency financial time series usually have fatter tails than normal distribution. In other words, large variations are more often to occur than a normal distribution would imply. Secondly, GARCH models capture volatility clustering discussed above. Moreover, despite of excessive volatility from time to time in financial markets, volatility will eventually settle down to a long run level. In GARCH model, the volatility "mean reverts" to its long run level.

Gold returns as for most of the commodities hold some stylized features as asymmetry and long-range dependence. To the best of our knowledge, our study is the first to assess the veracity of various volatility models for the behavior of the gold market in Turkey attributing to the asymmetry and long memory effects. We also measure the out-of-sample prediction power of these various models. In this study, we apply both linear specification models (GARCH, EGARCH, ARCH-M) and non-linear specification models (APGARCH and Component GARCH) to combine statistical approaches for modeling asymmetry and long memory at the same time. In the literature there is no reconciliation of a best fit model to explore conditional volatility, some studies provide strong support for component GARCH to capture the long memory volatility far more superior than the other GARCH models. However, some other studies argue that the simple non-parametric GARCH model outperforms the parametric models (Cheong, 2009; Vivian and Wohar, 2012). We aim to set a baseline to measure volatility persistence and asymmetry by conducting the linear specification models, while our effort shifts to long memory testing together with the asymmetry features in pertinence to the non-linear models.

A GARCH $(1,1)$ model is widely used and very common in financial time series to capture the series' own shock and volatility dynamics. A GARCH $(1,1)$ model infers that the conditional variance of the financial variable at time $t$ depends on its own shock (its squared error term) and its own volatility (its conditional volatility) in the previous period. It is argued that higher levels of current conditional volatility will increase the conditional volatility in the future which is termed as volatility persistence. Usually, a $\operatorname{GARCH}(1,1)$ model with three parameters is sufficient to capture volatility dynamics and to obtain a good model fit for financial time series.

A GARCH $(1,1)$ model can be written as follows;

$$
\sigma_{t}^{2}=\omega+\sum_{t=1}^{q} \alpha_{t} \varepsilon_{t-1}^{2}+\sum_{t=1}^{p} \beta_{t} \sigma_{t-1}^{2}
$$

where $\omega>0$ and $\alpha$ and $\beta \geq 0$ to ensure the positive conditional variance.

\subsection{Exponential GARCH (EGARCH)}

In ARCH/GARCH framework, symmetry is imposed on the conditional variance implying that positive and negative shocks have the same impact on the current volatility. However it is well known that many financial time series are influenced by negative shocks more than positive shocks. Plausible explanations for this are leverage and volatility feedback effects. Leverage effect points out that an increase in financial leverage level causes an increase in equity volatility level. Thus volatility rises more following a large price fall than following a price rise of the same magnitude. Volatility feedback effect explains how an increase in volatility may result in negative returns.

To capture the asymmetric response of financial variables, exponential GARCH (EGARCH) model is proposed by Nelson (1991);

$$
\log \left(h_{t}\right)=\omega+\sum_{j=1}^{q} \beta_{j} \log \left(h_{t-j}\right)+\sum_{i=1}^{p} \alpha\left|\frac{\varepsilon_{t-i}}{h_{t-i}}\right|+\sum_{k=1}^{r} \gamma_{k} \frac{\varepsilon_{t-k}}{h_{t-k}}
$$

where $\omega, \beta, \gamma$, and $\alpha$ are the model parameters.

EGARCH models the logarithm of conditional variance and an additional term is included in the model to account for asymmetries. Statistically significant and negative asymmetry term implies a leverage effect and asymmetric response of prices. In the context of stock markets, the EGARCH model is asymmetric since coefficient $\gamma$ is usually 
found to be negative. Hence, EGARCH model nests GARCH model in the sense that the model analyzes both the effect of past shocks and volatilities on the current variance. Furthermore, the EGARCH model allows good news and bad news to have a different influence on conditional variance. The EGARCH model also permits big news to have a greater effect on the variance than the standard GARCH model. In addition, the EGARCH model imposes no constraints on the parameters to ensure positivity of the conditional variance.

\subsection{ARCH in Mean (ARCH-M)}

Classical financial theory assumes that investors are rewarded with a higher return for taking extra risk. In order to actuate the concept, Engle, Lilien and Robins (1987) provided an ARCH-M model, letting a security's return be depended on its risk. The mean and variance equations can be described as follows;

$$
\begin{gathered}
y_{t}=\theta x_{t}+\delta \sigma_{t}^{2}+\varepsilon_{t,} \\
\sigma_{t}^{2}=\omega+\alpha(L) \varepsilon_{t-1}^{2}+\beta(L) \varepsilon_{t-1}^{2}
\end{gathered}
$$

If $\delta$ is statistically significant and positively valued, increased risk which is measured by a rise in the conditional variance, causes an increase in the mean return. Hence the coefficient $\delta$ can be described as a risk premium.

\subsection{Asymmetric Power GARCH}

Ding, Granger and Engle (1993) proposed asymmetric power GARCH model to account for asymmetry and a power term generated from the model automatically.

$$
\sigma_{t}^{2}=\omega+\sum_{i=!}^{q} \alpha_{i}\left(\left|\varepsilon_{t-i}\right|-\gamma_{i} \varepsilon_{t-i}\right)^{\delta}+\sum_{i=1}^{p} \beta_{i} \sigma_{t-i}^{\delta}
$$

It nests standard GARCH model for $\delta=2$ and $\gamma=0$, the EGARCH model for for $\delta=2$ and $0 \leq \gamma \leq 1$. The data is transformed by the power term, which changes the effect of the outliers to capture volatility clustering. The GARCH and the EGARCH models base data transformations on squared terms as can be seen from the above explanation. However for data series that do not display normal distribution features, it is not appropriate to use squared power transformation for describing the data series.

\subsection{News Impact Curves}

For GARCH-type models including asymmetry terms, the graphical representation of the asymmetry degree in volatility is given by "news impact curve" which is introduced by Pagan (1990). The news impact curve plots the next period volatility which results from positive and negative values of past shocks. Thus, it measures how new information is incorporated into volatility estimates. The news impact curve of GARCH model is a quadratic function centered around zero, implying that positive and negative shocks (news) of the same magnitude have same impact on the future conditional variance. If a negative return shock induces more volatility than a positive return shock of the same magnitude, the GARCH model under-predicts conditional future volatility arising from bad news and over-predicts the volatility arising from good news. Moreover, if large return shocks lead to more volatility than a quadratic function allows, GARCH model under-predicts volatility following a large return shock and over-predicts volatility following a small return shock. The EGARCH model has its minimum at $\varepsilon_{\mathrm{t}-1}=0$, and is exponentially rising in both directions of the curve but with different parameters.

\subsection{Component GARCH}

This model was proposed by Engle and Lee (1999) to incorporate long memory (persistence) property of time series. The variable exhibits persistency if autocorrelation of its absolute and squared values decay hyperbolically rather than exponentially. The model can mathematically be expressed as follows;

$$
\begin{aligned}
& h_{t}=q_{t}+\alpha\left(\varepsilon_{t-1}^{2}-q_{t-1}\right)+\beta\left(h_{t-1}-q_{t-1}\right) \\
& q_{t}=\omega+\rho q_{t-1}+\phi\left(\varepsilon_{t-1}^{2}-h_{t-1}\right)
\end{aligned}
$$

where, $q_{t}$ represents the long-run volatility which can also be considered as the past forecast error. 


\subsection{Forecasting Measurement}

In this study, we use three well known loss functions for assessing the out-of-sample forecasting accuracy; mean absolute error (MAE), mean absolute percentage error (MAPE) and Theil Inequality Coefficient (TIC).

$$
\begin{aligned}
& M A E=100 \sum_{t=T+1}^{T+h}\left|\hat{\sigma}_{t}-\sigma_{t}\right| / h \\
& M A P E=100 \sum_{t=T+1}^{T+h}\left|\frac{\hat{\sigma}_{t}-\sigma_{t}}{\sigma_{t}}\right| / h \\
& T I C=\sqrt{\sum_{t=T+1}^{T+h}\left(\hat{\sigma}_{t}-\sigma_{t}\right)^{2} / h} / \sqrt{\sum_{t=T+1}^{T+h} \hat{\sigma}_{t}^{2} / h}+\sqrt{\sum_{t=T+1}^{T+h} \sigma_{t}^{2} / h}
\end{aligned}
$$

Note that $\hat{\sigma}_{t}$ shows estimated value of the volatility, $\sigma_{t}$ is the actual value of the realized volatility and h indicates the forecast sample. The model producing smaller forecasting error (mean losses) outperforms the others in terms of forecasting performance.

Since, none of the measures is superior to the others and all of the measures have its drawbacks, we consider the above three alternatives to compare forecasting performances. The MAE is a robust evaluation of predictive accuracy, which is based on the loss function and therefore more sensitive to small deviations from zero and less sensitive to large deviations than the squared loss. The MAPE attains independence of scale, however many financial variables vary around 0 and if $\sigma_{t}$ then the MAPE is undefined. The TIC ranges between 0 and 1 , where 0 indicates perfect forecasting and 1 shows perfect inequality between the actual and forecasted values. However the TIC is totally dependent on the forecasts, as the estimations are in the denominator.

\section{Data}

We use daily data series of Istanbul Gold Exchange closing prices covering the period from January 4, 2006 to November 20, 2013.We compute $\log$ returns as $\mathrm{Rt}=\ln (\mathrm{Rt} / \mathrm{Rt}-1)$.We present raw, $\log$ returns and squared log returns of the series to provide a visual representation. In Figure 1, raw price series are plotted, providing evidence of rising prices in the last three years of the sample period. This is the result of the increased demand of gold as the stock markets slumped after 2008 mortgage crisis. The data for the most recent year (252 observations) is left out for out-of-sample forecasting analysis.

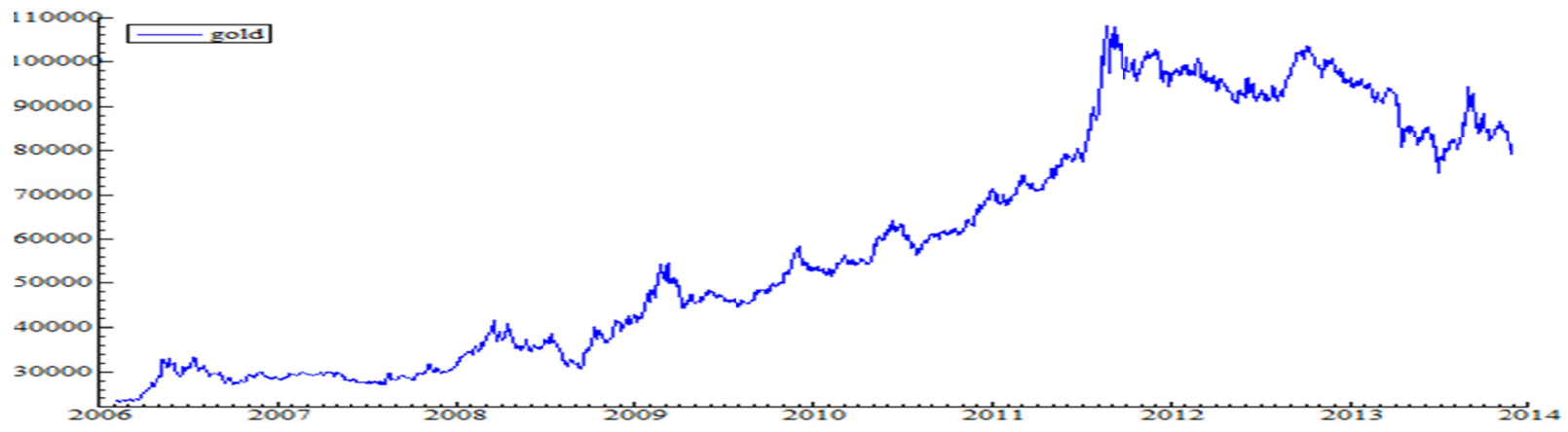

Figure 1. Raw price series

In Figure 2, we plot log returns of the prices. From the graph a well know phenomenon, volatility clustering in the returns can be observed, where large changes (small changes) are followed by large changes (small changes). 


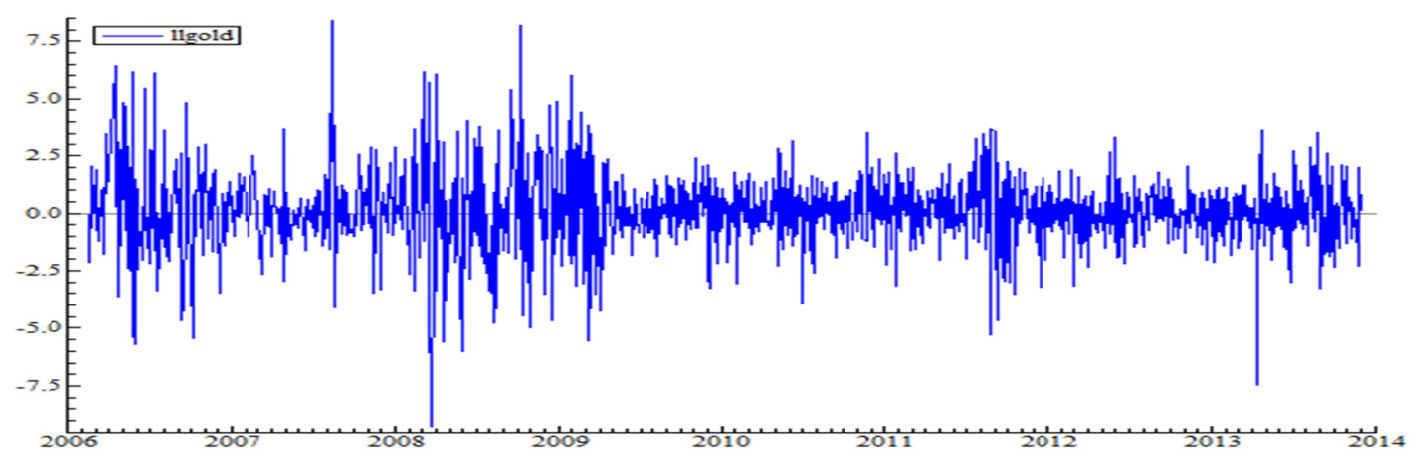

Figure 2. Log return series

In Figure 3, we provide squared returns of the log returns as a simple volatility proxy. Figure 3 shows that volatility in the gold returns reaches its peak between 2008 and 2009 when global stock markets and economies severely suffer from the US sub-prime mortgage crisis.

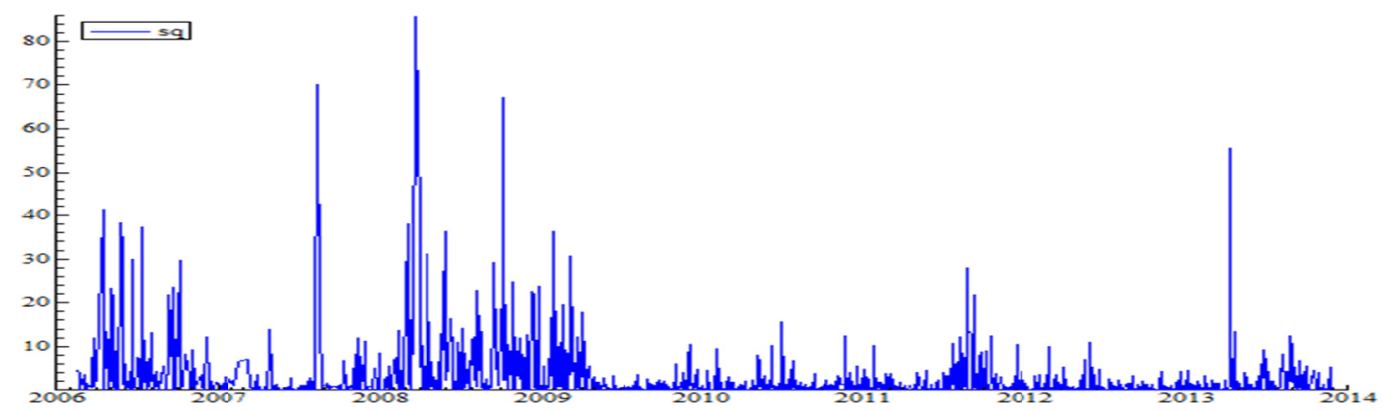

Figure 3. Squared log returns

We also analyze autocorrelations and partial autocorrelations of the return series. The autocorrelation function (ACF) measures a set of correlation coefficients between the series and lags of itself over time, while the partial autocorrelation function (PACF) is the partial correlation coefficients between the series and lags of itself over time. Generally, return series show a fast decay in autocorrelation and partial autocorrelation functions as can be seen in Figure 4.
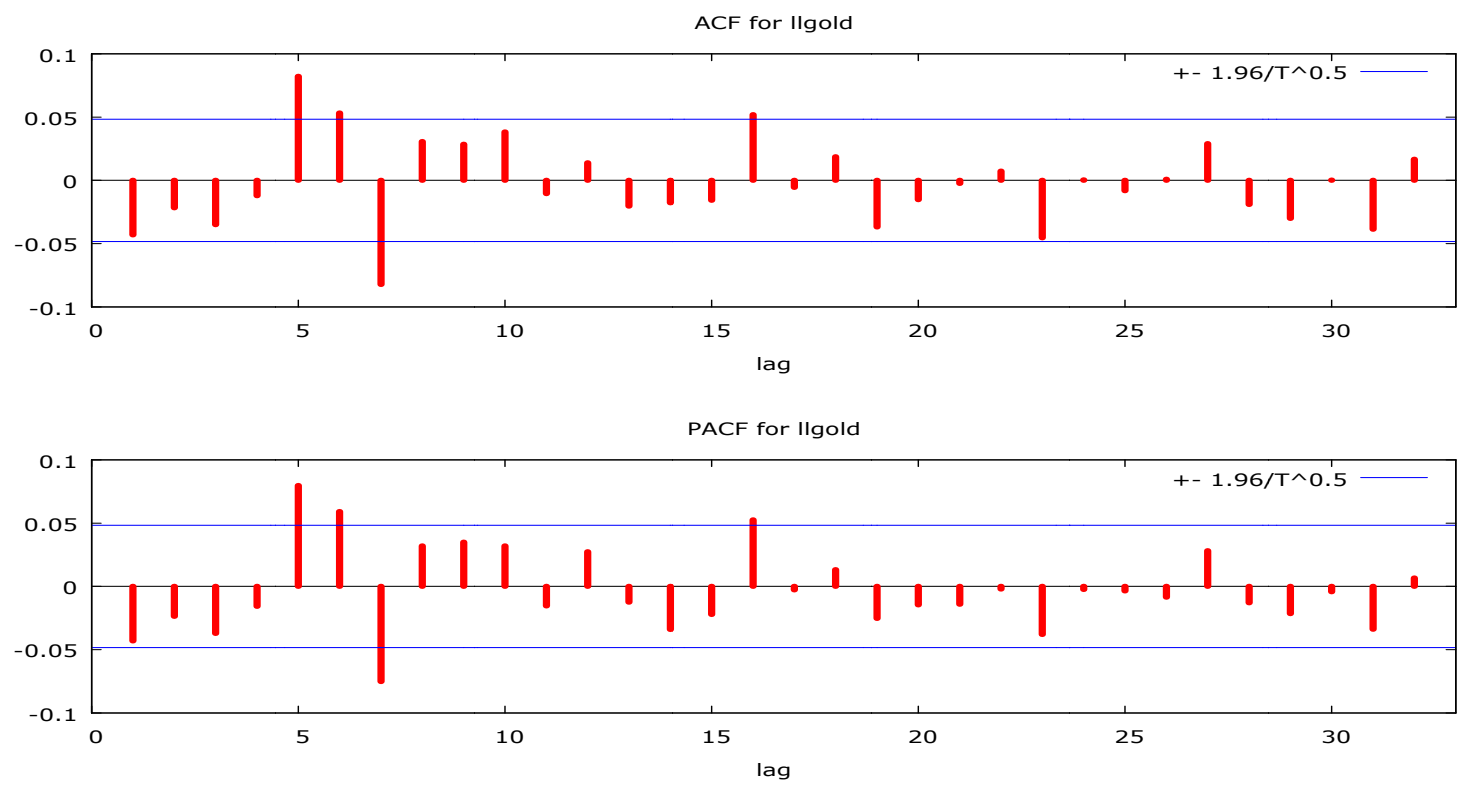

Figure 4. ACF and PACF functions of return series 
In order to examine whether the gold returns exhibit a persistence (long memory), autocorrelation and partial autocorrelation functions of the squared returns are plotted in Figure 5. As can be seen in figure 5, squared values of the returns are positive and significant up to 30 lags. They also exhibit a very slow decay with a hyperbolic rate, implying the volatility of gold returns have a long memory.
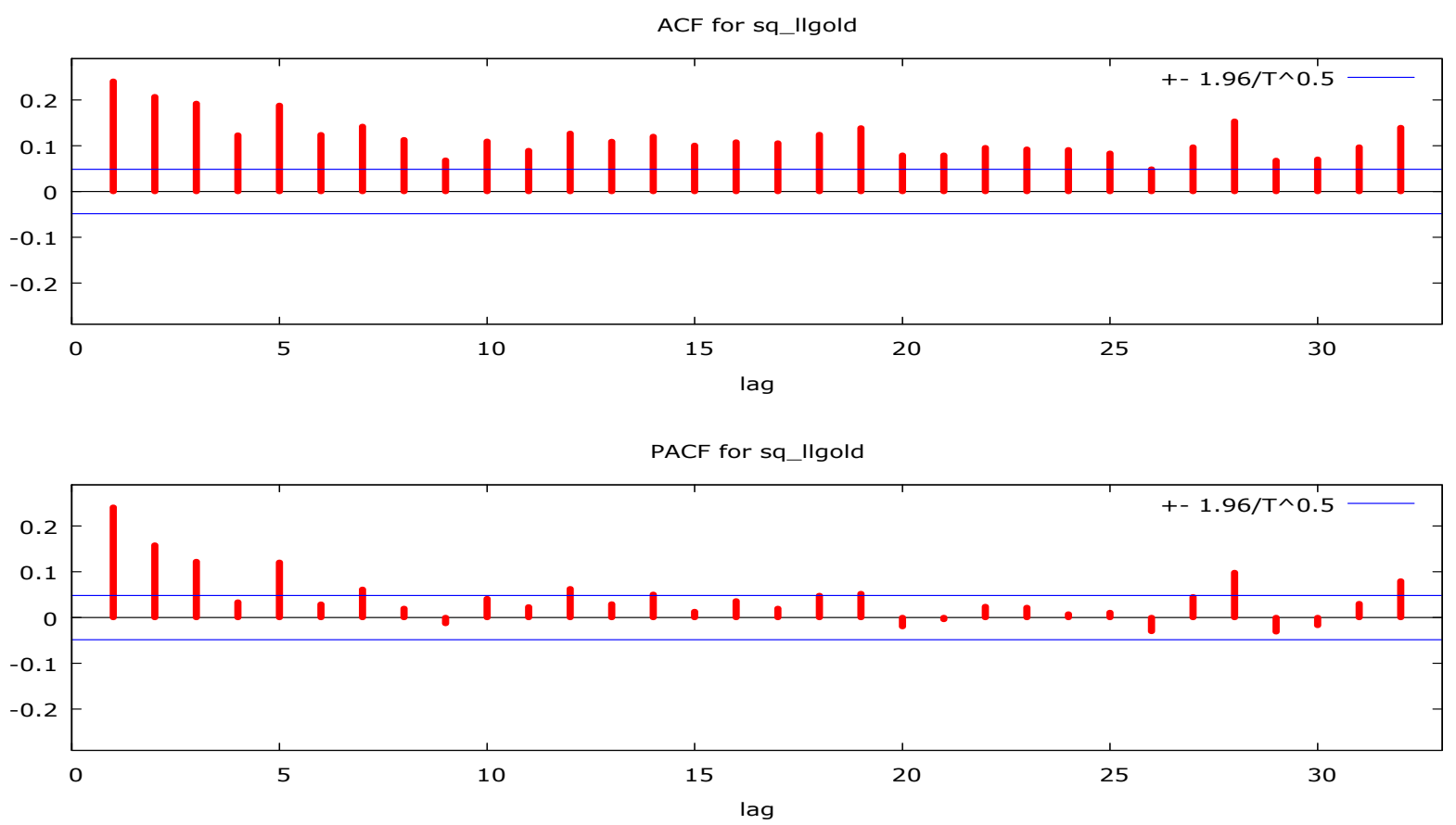

Figure 5. ACF and PACF functions of squared return series

In Table 1, we represent the descriptive statistics of the return series. The gold returns have a mean value of 0.07 and standard deviation of 1.48.The excess kurtosis (7.72) suggests that series have heavy (fat) tails relative to normal distribution with a kurtosis value of 3 and the skewness of 0.08 shows that the series are right skewed indicating that positive returns dominate negative returns in general. Jarque -Bera statistics with a null hypothesis of normal distribution, also suggest that gold return series are not normally distributed since we reject the null hypothesis at $1 \%$ significance level.

Table 1. Descriptive statistics

\begin{tabular}{lr}
\hline Mean & 0.075567 \\
Median & 0.029321 \\
Maximum & 8.376397 \\
Minimum & -9.258909 \\
Std. Dev. & 1.484313 \\
Skewness & 0.081345 \\
Kurtosis & 7.726834 \\
Jarque-Bera & 1532.306 \\
Probability & 0.000000
\end{tabular}

Sum

124.2327

Sum Sq. Dev.

3619.832

Observations

1644 


\section{Empirical Results}

\subsection{GARCH $(1,1)$ Model}

We firstly employ the GARCH model proposed by Bollorslev which examines past shocks and volatility on the current conditional volatility. In the case of gold returns, Table 2 shows that past shocks $(\alpha)$ and past volatility $(\beta)$ impact current conditional volatility. Moreover, their sums $(\alpha+\beta)$ are very close to unity meaning that volatility process is strongly persistent, which indicates long memory. We also examine residuals generated from GARCH (1, 1) model to check whether the model is correctly specified and produce reliable volatility estimates. In this regard, Table 3 provides evidence of an accurate model as the results show no serial correlation in standardized and squared residuals and no remaining $\mathrm{ARCH}$ effect.

Table 2. GARCH model results

\begin{tabular}{llll}
\hline$\mu$ & $\omega$ & $\alpha$ & $\beta$ \\
\hline 0.072 & 0.041 & 0.121 & 0.864 \\
$(0.031)$ & $(0.017)$ & $(0.031)$ & $(0.029)$ \\
\hline
\end{tabular}

Table 3. GARCH model diagnostics

\begin{tabular}{llllll}
\hline $\mathrm{Q}(20)$ & $\mathrm{Q}^{2}(20)$ & $\mathrm{ARCH}(10)$ & $\mathrm{AIC}$ & $\mathrm{SIC}$ & $\mathrm{LL}$ \\
\hline 24.929 & 11.036 & 0.045 & 3.344 & 3.359 & -2.3376 \\
{$[0.204]$} & {$[0.945]$} & {$[0.830]$} & & & \\
\hline
\end{tabular}

\section{2 $\operatorname{EGARCH}(1,1)$ Model}

Table 4 represents the empirical results of the exponential GARCH model. In the EGARCH framework, all of the coefficients are statistically significance at different significance levels. The conditional current volatility is found to be affected by past news (shocks), past volatility and asymmetry parameter.

Table 4. EGARCH model results

\begin{tabular}{lllll}
\hline$\mu$ & $\omega$ & $\gamma$ & $\alpha$ & $\beta$ \\
\hline 0.092 & -0.152 & 0.046 & 0.221 & 0.976 \\
$(0.030)$ & $(0.013)$ & $(0.014)$ & $(0.016)$ & $(0.004)$ \\
\hline
\end{tabular}

Table 5. EGARCH model diagnostics

\begin{tabular}{llllll}
\hline $\mathrm{Q}(20)$ & $\mathrm{Q}^{2}(20)$ & $\mathrm{ARCH}(10)$ & $\mathrm{AIC}$ & $\mathrm{SIC}$ & $\mathrm{LL}$ \\
\hline 26.814 & 12.415 & 0.364 & 3.342 & 3.349 & 2.3346 \\
{$[0.141]$} & {$[0.901]$} & {$[0.545]$} & & & \\
\hline
\end{tabular}

As indicated earlier, stock markets asymmetrically respond to the news, i.e. negative shocks affect volatility more than positive shocks. This situation is explained with "leverage effect", which implies that when stock prices fall in a levered firm, it leads to an increase in volatility. However, in the case of gold, we observe that the result is just the opposite. The asymmetry parameter is positive and statistically significant which shows that positive news (shocks) have more impact than negative news (shocks) in Istanbul Gold Exchange. Table 5 shows that the exponential GARCH model is correctly specified implying no serial correlation in the standardized residuals and no remaining ARCH effects.

In order to graphically represent the asymmetric responses, we draw the news impact curve which depicts the relationship between the news and future volatility conditional on the information up to current time. The news impact curve plots news scenarios that is a range of bad and good news, on the horizontal axis, against the resulting volatility plotted on the vertical axis. Figure 6 shows the news impact curve generated from EGARCH $(1,1)$ model and shows the reversed asymmetry in the volatility process implying the dominance of positive shocks compared to negative ones. 


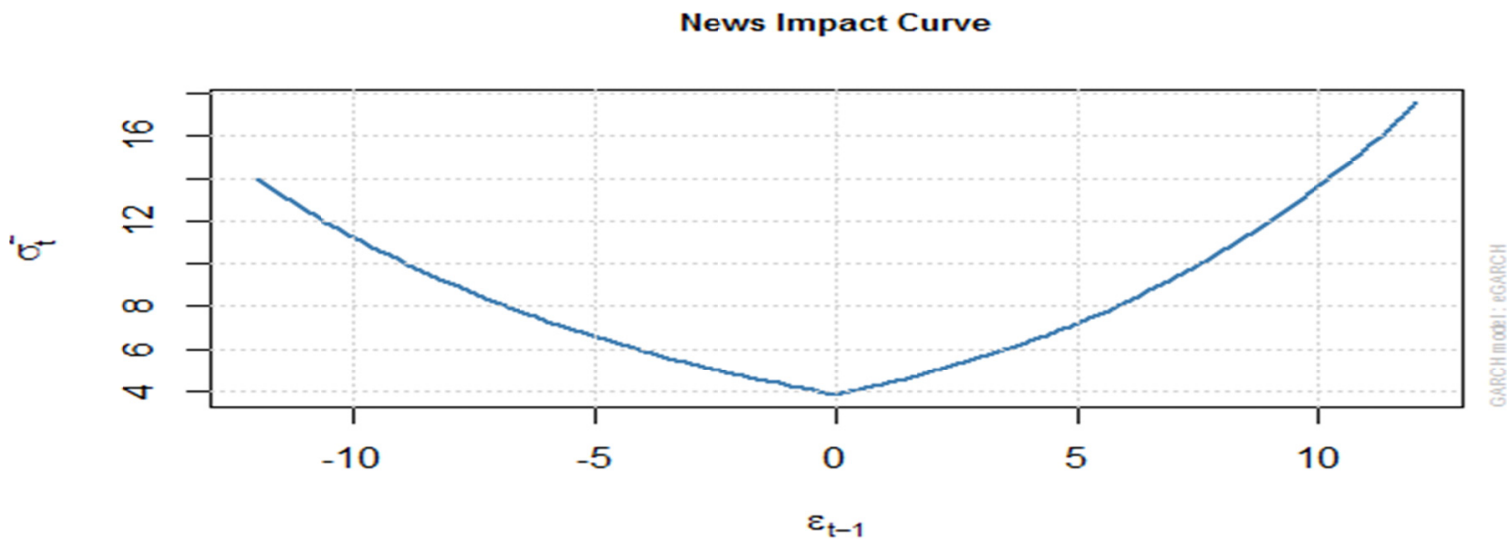

Figure 6. News impact curve generated from $\operatorname{EGARCH}(1,1)$

\section{$6.3 \operatorname{GARCH}-M(1,1)$}

In the financial markets it is well known that higher returns are associated with higher risk which is measured by volatility. GARCH in mean volatility model is proposed to test this well-known phenomenon.

Table 6 represents the results and suggest that in the case of the gold market in Turkey, as the related risk rises, return does not increase, which is observed by the insignificance of the parameter $\delta$. Table 7 shows the diagnostic checking and adequacy of the model residuals.

Table 6. GARCH-M model results

\begin{tabular}{lllll}
\hline$\mu$ & $\omega$ & $\delta$ & $\alpha$ & $\mathrm{B}$ \\
\hline 0.054 & 0.041 & 0.016 & 0.121 & 0.863 \\
$(0.084)$ & $(0.008)$ & $(0.074)$ & $(0.011)$ & $(0.011)$ \\
\hline
\end{tabular}

Table 7. GARCH-M model diagnostics

\begin{tabular}{llllll}
\hline $\mathrm{Q}(20)$ & $\mathrm{Q}^{2}(20)$ & $\mathrm{ARCH}(10)$ & $\mathrm{AIC}$ & $\mathrm{SIC}$ & $\mathrm{LL}$ \\
\hline 24.800 & 10.996 & 0.046 & 3.346 & 3.364 & -2.3372 \\
{$[0.209]$} & {$[0.946]$} & {$[0.828]$} & & & \\
\hline
\end{tabular}

\subsection{Asymmetric Power GARCH $(1,1)$}

Asymmetric Power GARCH model proposed by Ding and Granger (1996) captures both asymmetry and power term, arguing that power term should be automatically estimated by the model rather than being imposed by the researchers. Unlike the exponential GARCH model, if asymmetry term is found to be positive and statistically significant, negative shocks are more dominant relative to the positive ones.

Table 8 shows the results of the APARCH model implying that past news and volatility significantly affect current volatility. Besides asymmetry term ascertains that positive shocks influence volatility compared to negative shocks. Hence the result of the APARCH model is consistent with the EGARCH model in terms of sign and presence of asymmetry. Table 9 presents diagnostic tests of the results suggesting that the model is correctly specified.

Table 8. APARCH Model results

\begin{tabular}{lllll}
\hline$\mu$ & $\omega$ & $\gamma$ & $\alpha$ & $\beta$ \\
\hline 0.098 & 0.038 & -0.095 & 0.147 & 0.883 \\
$(0.030)$ & $(0.006)$ & $(0.020)$ & $(0.016)$ & $(0.009)$ \\
\hline
\end{tabular}


Table 9. APARCH model diagnostics

\begin{tabular}{llllll}
\hline $\mathrm{Q}(20)$ & $\mathrm{Q}^{2}(20)$ & $\mathrm{ARCH}(10)$ & $\mathrm{AIC}$ & $\mathrm{SIC}$ & $\mathrm{LL}$ \\
\hline 27.295 & 10.656 & 0.130 & 3.335 & 3.354 & -2.3298 \\
{$[0.127]$} & {$[0.955]$} & {$[0.717]$} & & & \\
\hline
\end{tabular}

As a visual representation, we also provide the news impact curve to distinguish between the signs of the shocks. As can be seen from Figure 7, positive shocks are more dominant than the negative ones, which is consistent with the finding of the EGARCH model.

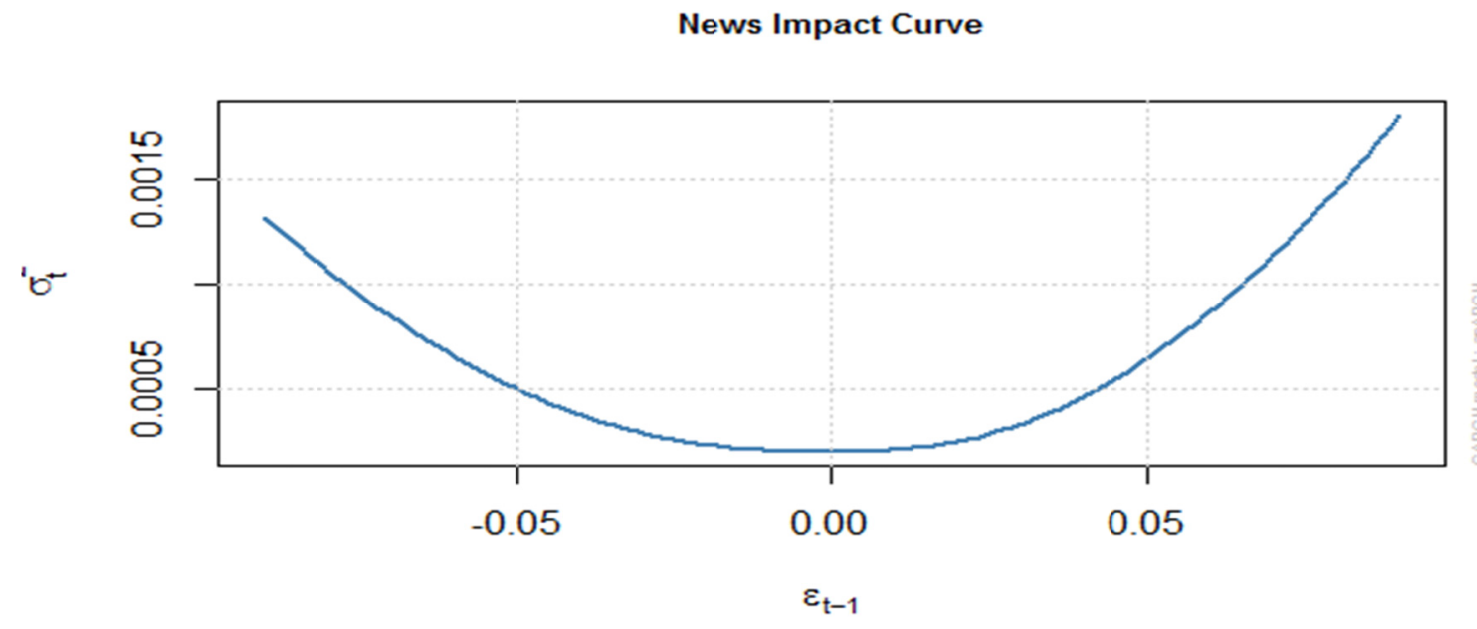

Figure 7. News Impact curve generated from APARCH $(1,1)$ model

\subsection{Component $\operatorname{GARCH}(1,1)$}

Component GARCH model of Engle and Lee (1999) is proposed to capture persistence in the volatility process by separating permanent and transitory variances. In Table 10, we present the empirical results of the model. The parameters of transitory component $(\alpha+\beta)$ is smaller than the other employed GARCH models (GARCH, EGARCH, GARCH-M, and APARCH). Hence we can draw the conclusion that the short run volatility component is weak. On the other hand, long run volatility component $(\rho)$ is estimated as close to unity indicating that permanent component of the conditional variance is very strong.

Table 11 indicates that component GARCH model is correctly specified in terms of insignificant serial correlations and remaining ARCH effects. Thus, we can state that the model is able to capture long memory (persistence) in the volatility process of the gold market in Turkey.

Table 10. Component GARCH Model Results

\begin{tabular}{llllll}
\hline$\mu$ & $\omega$ & $\gamma$ & $\delta$ & $\alpha$ & $\beta$ \\
\hline 0.099 & 0.036 & -0.261 & 1.736 & 0.100 & 0.887 \\
$(0.030)$ & $(0.006)$ & $(0.065)$ & $(0.313)$ & $(0.011)$ & $(0.011)$ \\
\hline
\end{tabular}

Table 11. Component GARCH Model Diagnostics

\begin{tabular}{llllll}
\hline $\mathrm{Q}(20)$ & $\mathrm{Q}^{2}(20)$ & $\mathrm{ARCH}(10)$ & $\mathrm{AIC}$ & $\mathrm{SIC}$ & $\mathrm{LL}$ \\
\hline 27.231 & 11.123 & 0.219 & 3.336 & 3.358 & -2.3295 \\
{$[0.129]$} & {$[0.943]$} & {$[0.639]$} & & & \\
\hline
\end{tabular}


Overall, the employed models suggest that current volatility of Istanbul Gold Exchange is significantly affected by its own past shocks and volatility. Furthermore, the models incorporating asymmetry term (EGARCH, APARCH), provide empirical evidence of reversed asymmetry, demonstrating that sudden surprise positive events provoke a larger response than negative shocks of equal magnitude. Additionally, volatility process is persistent indicating that gold returns in Turkey can be predicted by portfolio managers or investors.

\subsection{Forecasting Results}

Tables 12, 13 and 14 represents 1,5 and 20 days- ahead forecasting performances respectively measured by three evaluation criteria namely, MAE (Mean Absolute Error), MAPE (Mean Absolute Percentage Error), TIC (Theil Inequality Coefficient). We evaluate out of sample gold price volatility forecasts for the period from January 2, 2013 to November 20, 2013. From Table 12 to Table 14, we can observe that all of the three criteria produce similar results. However, as it can be seen from the following tables, in most of the cases, the EGARCH model outperforms the other models for all forecasting horizons, i.e. 1, 5 and 20-days-ahead, producing the lowest forecast errors. CGARCH model only produce the best forecasting results, in MAPE for the 1- and 5-days-ahead and MAE for the 5 and 20-days-ahead forecasting analysis.

Table 12. 1- day-ahead forecasting performances of the models

\begin{tabular}{llllll}
\hline & GARCH & EGARCH & ARCH-M & APARCH & CGARCH \\
\hline MAE & 0.332 & 0.329 & 0.330 & 0.342 & 0.652 \\
MAPE & 0.587 & 0.583 & 0.585 & 0.605 & 0.343 \\
TIC & 0.227 & 0.225 & 0.226 & 0.232 & 0.671 \\
\hline
\end{tabular}

Table 13. 5- days-ahead forecasting performances of the models

\begin{tabular}{llllll}
\hline & GARCH & EGARCH & ARCH-M & APARCH & CGARCH \\
\hline MAE & 0.739 & 0.733 & 0.738 & 0.740 & 0.576 \\
MAPE & 0.430 & 0.427 & 0.430 & 0.429 & 0.240 \\
TIC & 0.6096 & 0.607 & 0.609 & 0.609 & 0.782 \\
\hline
\end{tabular}

Table 14. 20- days-ahead forecasting performances of the models

\begin{tabular}{llllll}
\hline & GARCH & EGARCH & ARCH-M & APARCH & CGARCH \\
\hline MAE & 0.891 & 0.885 & 0.891 & 0.865 & 0.779 \\
MAPE & 0.108 & 0.107 & 0.108 & 0.108 & 0.245 \\
TIC & 0.521 & 0.520 & 0.521 & 0.515 & 0.942 \\
\hline
\end{tabular}

\section{Conclusion}

In this study, we assess the volatility dynamics of Istanbul Gold Exchange via different GARCH-class models. At a first glance, we observe that current conditional volatility of gold prices is significantly impacted by its own past shocks (news) and volatility. Furthermore, employing volatility models which takes asymmetry into account, EGARCH and APARCH model results suggest the presence of asymmetry however, unlike the equity markets, we observe that sign of the asymmetry is reversed implying that positive shocks are more dominant than the negative ones. Additionally, component GARCH model results show that short term component of volatility is weaker than the permanent component. For this reason we can draw a conclusion that persistence exists in the volatility process of Istanbul Gold Exchange. Forecasting results of the models reveal that the EGARCH and CGARCH models are superior to other GARCH-class models employed in the study. Hence, the findings of the study show that the models which include asymmetry and long-range dependence produce the lowest error measures in the forecasting procedure. Our results are indicative for portfolio managers and investors who employ gold as a hedge instrument in their portfolio risk management practices. 


\section{References}

Arouri, M. E. H., Hammoudeh, S., Lahiani, A., \& Nguyen, D. K. (2012). Long memory and structural breaks in modeling the return and volatility dynamics of precious metals. The Quarterly Review of Economics and Finance, 52(2), 207-218. http://dx.doi.org/10.1016/j.qref.2012.04.004

Batten, J. A., Ciner, C., \& Lucey, B. M. (2010). The macroeconomic determinants of volatility in precious metals markets. Resources Policy, 35(2), 65-71. http://dx.doi.org/10.1016/j.resourpol.2009.12.002

Baur, D. (2011). Asymmetric Volatility in the Gold Market. Available at SSRN 1526389.

Baur, D. G., \& Lucey, B. M. (2010). Is gold a hedge or a safe haven? An analysis of stocks, bonds and gold. Financial Review, 45, 217-229. http://dx.doi.org/10.1111/j.1540-6288.2010.00244.x

Baur, D. G., \& McDermott, T. K. (2010). Is gold a safe haven? International evidence. Journal of Banking and Finance, 34, 1886-1898. http://dx.doi.org/10.1016/j.jbankfin.2009.12.008

Bekaert, G., \& Wu, G. (2000). Asymmetric volatility and risk in equity markets. Review of Financial Studies, 13, 1-42. http://dx.doi.org/10.1093/rfs/13.1.1

Bollerslev, T. (1986). Generalized autoregressive conditional heteroscedasticity. Journal of Econometrics, 31, 307-327.

Brooks, C. (2008). Introductory econometrics for finance. Cambridge university press.

Cai, J., Cheung, Y.-L., \& Wong, M.C.S. (2001). What moves the gold market? Journal of Futures Markets, 21, 257-278. http://dx.doi.org/10.1002/1096-9934(200103)

Campbell, J. Y., \& Hentschel, L. (1992). No news is good news: An asymmetric model of changing volatility in stock returns. Journal of Financial Economics, 31, 281-318. http://dx.doi.org/10.1016/0304-405X(92)90037-X

Canarella, G., \& Pollard, S. K. (2008). Modelling the volatility of the London gold market fixing as an asymmetric power ARCH. The Journal of Applied Finance, 14(5), 17-43.

Capie, F., Mills, T. C., \& Wood, G. (2005). Gold as a hedge against the dollar. Journal of International Financial Markets, Institutions and Money, 15(4), 343-352. http://dx.doi.org/10.1016/j.intfin.2004.07.002

Chandar, N., Patro, D.K., \& Yezegel, A. (2009). Crises, contagion and cross-listings. Journal of Banking and Finance, 33, 1709-1729. http://dx.doi.org/10.1016/j.jbankfin.2009.04.003

Cheong, C.W. (2009). Modeling and forecasting crude oil markets using ARCH-type models. Energy Policy, 37, 2346-2355. http://dx.doi.org/10.1016/j.enpol.2009.02.026

Chkili, W., Hammoudeh, S., \& Nguyen, D. K. (2014). Volatility forecasting and risk management for commodity markets in the presence of asymmetry and long memory. Energy Economics, 41, 1-18. http://dx.doi.org/10.1016/j.eneco.2013.10.011

Christie, A. A. (1982). The stochastic behavior of common stock variances-Value, leverage and interest rate effects. Journal of Financial Economics, 10, 407-432. http://dx.doi.org/10.1016/0304-405X(82)90018-6

Conover, C. M., Jensen, G. R., Johnson, R. R., \& Mercer, J. M. (2009). Can precious metals make your portfolio shine? Journal of Investing, 18, 75-86. http://dx.doi.org/10.3905/JOI.2009.18.1.075\#sthash.qxGo37LP.dpuf

Ding, Z., Granger, C. W., \& Engle, R. F. (1993). A long memory property of stock market returns and a new model. Journal of empirical finance, 1(1), 83-106. http://dx.doi.org/10.1016/0927-5398(93)90006-D

Ding, Z., \& Granger, C. W. (1996). Modeling volatility persistence of speculative returns: a new approach. Journal of econometrics, 73(1), 185-215. http://dx.doi.org/10.1016/0304-4076(95)01737-2

Dornbusch, R., Park, Y., \& Claessens, S. (2000). Contagion: how it spreads and how it can be stopped. World Bank Research Observer, 15, 177-197. http://dx.doi.org/10.1.1.195.1918

Engle, R. F. (1982). Autorregresive Conditional Heteroskedasticity with estimates of the variance of UK inflation. Econometrica, 50, 987-1008.

Engle, R. F., \& Lee, G. (1999). A long-run and short-run component model of stock return volatility. Cointegration, Causality, and Forecasting: A Festschrift in Honour of Clive WJ Granger, 475-497.

Engle, R. F., Lilien, D. M., \& Robins, R. P. (1987). Estimating time varying risk premia in the term structure: the ARCH-M model. Econometrica: Journal of the Econometric Society, 391-407. 
Francis, B.B., Hasan, I., \& Sun, X. (2008). Financial market integration and the value of global diversification: evidence for US acquirers in cross-border mergers and acquisitions. Journal of Banking and Finance, 32, 1522-1540. http://dx.doi.org/10.1016/j.jbankfin.2007.10.013

Ghosh D., Levin, E. J., MacMillan, D., \& Wright, R. E. (2004). Gold as an inflation hedge? Studies in Economics and Finance, 22(1), 1-25. http://dx.doi.org/10.1108/eb043380

Hammoudeh, S., Malik, F., \& McAleer, M. (2011). Risk management of precious metals. Quarterly Review of Economics and Finance, 51, 435-441. http://dx.doi.org/10.1016/j.qref.2011.07.002

Hammoudeh, S., \& Yuan, Y. (2008). Metal volatility in presence of oil and interest rate shocks. Energy Economics, 30(2), 606-620. http://dx.doi.org/10.1016/j.eneco.2007.09.004

Hammoudeh, S. M., Yuan, Y., McAleer, M., \& Thompson, M. A. (2010). Precious metals-exchange rate volatility transmissions and hedging strategies. International Review of Economics \& Finance, 19(4), 633-647. http://dx.doi.org/10.1016/j.iref.2010.02.003

Hillier, D., Draper, P., \& Faff, R. (2006). Do precious metals shine? An investment perspective. Financial Analysts Journal, 62, 98-106.

Hood, M., \& Malik, F. (2013). Is gold the best hedge and a safe haven under changing stock market volatility? Review of Financial Economics, 22, 47-52. http://dx.doi.org/10.1016/j.rfe.2013.03.001

Jaffe, J. F. (1989, March/April). Gold and gold stocks as investments for institutional portfolios. Financial Analysts Journal, 53-59.

Joy, M. (2011). Gold and the US dollar: Hedge or haven? Finance Research Letters, 8(3), 120-131. http://dx.doi.org/10.1016/j.frl.2011.01.001

Kitchen, J. (1996). Domestic and international financial market responses to federal deficit announcements. Journal of International Money and Finance, 15, 239-254. http://dx.doi.org/10.1016/0261-5606(96)00003-4

Lawrence, C. (2003). Why is Gold Different from Other Assets? An Empirical Investigation. World Gold Council, London.

Levin, E. J., Montagnoli, A., \& Wright, R.E. (2006). Short-run and long-run determinants of the price of gold. World Gold Council Report, Research Study No. 32, Business School, London.

Mahdavi, S., \& Zhou, S. (1997). Gold and commodity prices as leading indicators of inflation: tests of long-run relationship and predictive performance. Journal of Economics and Business, 49(5), 475-489. http://dx.doi.org/10.1016/S0148-6195(97)00034-9

McCown, J. R., \& Zimmerman, J. R. (2006). Is Gold a Zero-Beta Asset? Analysis of the Investment Potential of Precious Metals. July 24. Precious Metals. http://dx.doi.org/10.2139/ssrn.920496

McKenzie, M., Mitchell, H., Brooks, R., \& Faff, R. (2001). Power arch modelling of commodity futures data on the London metal exchange. European Journal of Finance, 7, 22-38. http://dx.doi.org/10.1080/13518470123011

Mills, T.C. (2003). Statistical analysis of daily gold price data. Physica A, 338(3-4), 559-566. http://dx.doi.org/10.1016/j.physa.2004.03.003

Morales, L. (2008, January). Volatility spillovers on precious metals markets: the effects of the Asian crisis. In Conference papers (p. 5).

Morales, L., \& Andreosso-O'Callaghan, B. (2011). Comparative analysis on the effects of the Asian and global financial crises on precious metal markets. Research in International Business and Finance, 25(2), 203-227. http://dx.doi.org/10.1016/j.ribaf.2011.01.004

Nakamura, T., \& Small, M. (2007). Tests of the random walk hypothesis for financial data. Physica A, 377, 599-615. http://dx.doi.org/10.1016/j.physa.2006.10.073

Narayan, P. K., Narayan, S., \& Zheng, X. (2010). Gold and oil futures markets: Are markets efficient? Applied Energy, 87(10), 3299-3303. http://dx.doi.org/10.1016/j.apenergy.2010.03.020

Nelson, D. B. (1991). Conditional heteroskedasticity in asset returns: A new approach. Econometrica: Journal of the Econometric Society, 347-370. http://dx.doi.org/10.1016/B978-012598275-7.50004-1

Pagan, A. R. (1990). Alternative models for conditional stock volatility. Journal of Econometrics, 45(1), 267-290. http://dx.doi.org/10.1016/0304-4076(90)90101-X 
Riley, C. (2010). A new gold rush: Investing in precious metals. Journal of Investing, 19, 95-100.

Sari, R., Hammoudeh S., \& Soytas U. (2010). Dynamics of oil price, precious metal prices, and exchange rate. Energy Economics, 32(2), 351-362. http://dx.doi.org/10.1016/j.eneco.2009.08.010

Shafiee, S., \& Topal, E. (2010). An overview of global gold market and gold price forecasting. Resources Policy, 35, 178-189. http://dx.doi.org/10.1016/j.resourpol.2010.05.004

Soytas, U., Sari, R., Hammoudeh, S., \& Hacihasanoglu, E. (2009). World oil prices, precious metal prices and macroeconomy in Turkey. Energy Policy, 37(12), 5557-5566. http://dx.doi.org/10.1016/j.enpol.2009.08.020

Trück, S., \& Liang, K. (2012). Modelling and forecasting volatility in the gold market. International Journal of Banking and Finance, 9(1), 3.

Tully, E. \& Lucey, B. M. (2006). Seasonality, risk and return in daily COMEX gold and silver data. Applied Financial Economics, 16(4), 319-333. http://dx.doi.org/10.1080/09603100500386586

Tully, E., \& Lucey, B. M. (2007). A power GARCH examination of the gold market. Research in International Business and Finance, 21(2), 316-325. http://dx.doi.org/10.1016/j.ribaf.2006.07.001

Vivian, A., \& Wohar, M. E. (2012). Commodity volatility breaks. Journal of International Financial Markets, Institutions and Money, 22(2), 395-422. http://dx.doi.org/10.1016/j.intfin.2011.12.003

Zhang, Y. J., \& Wei, Y. M. (2010). The crude oil market and the gold market: Evidence for cointegration, causality and price discovery. Resources Policy, 35(3), 168-177. http://dx.doi.org/10.1016/j.resourpol.2010.05.003 